be superfluous to describe the disease as it affects the female. A precisely similar enlargement is not uncommon in the pudenda of females in Hindustan, the excision of which is very simple. There is just such a case at present in St. George's Hospital, of small size in comparison to the enormous ones in warm climates, where they have been known to extend below the knees and to weigh thirty pounds.

The disorder is a pure sarcoma of organized lymph, and is evidently the same disease as that which occurs in the West Indies, in Africa, Ceylon, and occasionally in Europe, and which has occurred in the practice of Delpech, Liston, Clot, and other surgeons.

Fig. 7 .

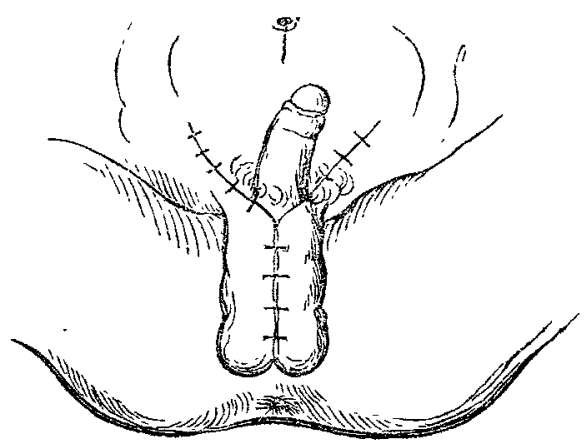

FIG. 8 .

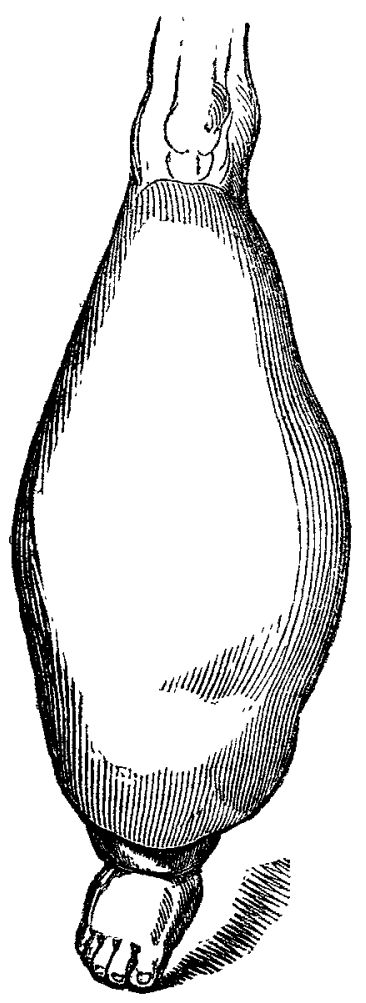

Fig. 7 represents the appearance, after dressing the wounds and reflecting the elongated prepuce.

Fig. 8 exhibits the appearance of the disease when it pervades the lower extremities.

Dorset-street, Portman-square, Jan. 1846.

\section{ON THE VALUE OF QUININE IN AFRICAN REMITTENT FEVER.}

By Thomas R. H. Thomson, Esq., M.R.C.S. Eng., R.N., Edin.

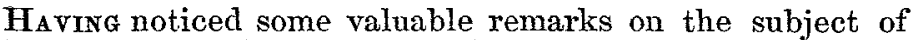
yellow fever, by Mr. Birtwhistle, Surgeon R.N., in Tre Lancet of the 3rd Jan., and in which he refers to the use of quinine in that disease, $I$ beg to add a few statements of its efficacy as a remedy in African remittent fever, and confirmatory of Mr.Birtwhistle's observations. While acting surgeon of H.M.S. "Soudan," engaged on the Niger Expedition, in 1841-2, I had an opportunity of trying it in conjunction with chloride of mercury, in a few cases of primary fever. It certainly answered fully; but I believe it would have proved more valuable had I not restricted the quantity to two or threegrain doses.
Of its effect in the secondary and tertiary attacks of African remittent, which are certainly attended with worse-looking and more violent symptoms than the primary, it may almost be considered a specific. The first trials I made of it were at Fernando Po, in Dec. 1841, when left in charge of the sick. At that time the "Harmattan" prevailed, and although this is considered a healthy season on other parts of the West Coast, it was most decidedly the reverse at that island. All the few Europeans (old residents and well-seasoned, as far as this can be accomplished by prior attack, \&c.) were laid up with remittent fever of a low character ; and in all their cases I gave the quinine in doses of eight and ten grains daily, with perfect success. This induced me to try it in other cases of secondary fever, on board ship; and although in some of them the tongue was dry, foul, and cracked, with every indication of high febrile excitement, yet it had the effect of arresting the bad symptoms. Let me give you one short extract from the official journal forwarded to Sir William Burnett, Medical Director-general H.M. navy, (from the case of Mr. Anderson, entered on the sick list, April 30th, 1842.) - "May 10th.-The remissions have become very obscure; skin burning hot; occasional low delirinm; rapid, jerking, but weak pulse; the bowels have been kept freely opened by seidlitz, \&c. The tongue remarkably foul and dry. And both Dr. Pritchett (who also saw him at my request) and myself began to entertain unfavourable views of his recovery. I therefore determined to try the effects of quinine; and accordingly ten grains were given on the evening of the 10th.

"Continued restless during the night, but slept a little towards morning, and was relieved by a gentle perspiration. On the 11th, a very perceptible remission took place, and the guinine was again administered at noon, in an eight-grain dose. This was repeated for the three following days, when the fever gradually declined; and on the $20 \mathrm{th}$, he was so far recovered, as to be discharged to partial duty, there being no other executive officer on board at the time.

"In this case, as in all the secondary attacks of remittent fever in which this remedy was tried, it produced a most marked and beneficial effect; and, strange to mention, although the tongue was in most of them foul and dry prior the administration of the quinine, it very soon became moist and clean."-(From H.M.S. Soudan's medical journal, 1841-2.)

Subsequently, in 1844, while employed in the Rio de ta Plata, I was induced to try it in some slight cases of typhoid fever, in whom there existed considerable depression, a rapid pulse, and foul tongue, unaffected by purgatives; and it had the most rapid and satisfactory effect: and I think it well worthy of a fair trial in this country in typhus; but $I$ should hesitate to use it in small doses, say two or three grains: my impression, as deduced from observations on its modus operandi, being, that in small quantity it only acts as a temporary stimulant, thereby producing more harm than good-given in a full dose, from six to ten grains, it would seem to have a different and specific action.

In all the cases in which I tried it in the African remittent, it reduced the number, but increased the momentum and roundness of the pulse. Connected with this subject, $\mathbf{I}$ would wish to bring under the consideration of medical officers serving on the West Coast of Africa-whether quinine in full doses has the power or not of warding off entirely the remittent fever?

It had long been known that persons affected with any form of intermittent fever on that coast enjoyed a certain immunity from the remittent, as pointed out by the late Mr. Boyle in his work on diseases of Africa; I therefore reasoned that if quinine was known to overcome the intermittent, that remedy might be used in full doses, and produce such an effect on the system as would prevent the attack of the other and worse form of fever, which is warded off by the presence of intermittent.

On my return to the West Coast from Ascension, in 1842, I determined to commence the experiment in my own person, taking daily one or two full doses of quinine; and although I may with truth say that I was more exposed than any other person to the exciting and predisposing causes of remittent fever-being almost continually on shore and in the woods, collecting specimens of natural history, and in obtaining information about the natives at Fernando Po, Bimbia, Came roons, \&c.-I quite escaped both forms of fever. On being ordered to England, in August 1842, I considered it necessary to reduce gradually the quantum of quinine; and just before arriving home, had left it off entirely: when, strange to say, I was for the first time attacked with tertian ague in England, under which I suffered for some time; and it returned again at the same season, September, in the following year. 
It must not be supposed that, in thus calling attention to the trial of quinine, I wish to advocate its indiscriminate use in all forms of fever. On the contrary, my opinion has always been, that nothing tends to bring discredit sooner on our best remedies, than attempting to place them on the footing of general specifics, or quack nostrums.

Montague-street, Edinburgh, Jan. 1846.

\section{REPORT OF A CASE OF PUERPERAL CONVUL} SIONS, IN WHICH BLEEDING AND OPIUM WERE SUCCESSFULLY EMPLOYED.

By Geo. Henry Bore, Esq., M.R.C.S.E., Copford.

THE following case of puerperal convulsions, which lately occurred in my practice, appears to me to be highly interesting in a practical point of view, showing as it does the immense benefit resulting from the exhibition of that much disputed remedy, opium, in this frightful disorder, as I feel satisfied that the more approved treatment would not have led to a successful termination had that remedy been omitted.

Emma S-- aged seventeen, of small stature, and light complexion, was seized with convulsions about noon on the 31st of December last. She was in the eighth month of pregnancy, and had been lately rather desponding, on account of her situation, (being ummarried,) but her general health had not materially suffered. She had always enjoyed the best of health, and had never been the subject of epilepsy. On the morning of the attack she had not felt as well as usual, on which account she had not risen at her usual hour, but had not complained of headach, or any other symptom which might have been considered premonitory of her alarming seizure.

On my arrival at one P.M., I found her just recovered from her second fit; consciousness partially restored; pulse 90 , small and labouring; no appearance of labour being instituted. I immediately bled her to twenty ounces, and administered fitteen grains of calomel. The bleeding appeared to relieve the system considerably, and, having another pressing case on hand, I left, with strict injunctions to be sent for in the event of a recurrence of the convulsions. In the afternoon I was again summoned, and was with her about six o'clock, when I learned that she had been again seized at three P.M., and had had eight more fits: pulse 100 , and fuller than in the morning. I immediately tied up her arm and bled her to the amount of thirty ounces, from a large orifice from which the blood flowed in a full stream -another convulsion during the operation. Upon examination per vaginam $I$ found the os uteri dilated so as to admit the index finger, membranes unruptured, presentation natural; as the bladder had not been relieved, I introduced the catheter and drew off about four ounces of rather high-coloured urine: feet and legs cold. Applied hot bottles and friction. She continued free from any return of the convulsions for three hours, but in a state of coma; there appeared to be no effort of the uterus to discharge its contents, except when the condition of the os was examined, which continued gradually to dilate. At nine P.M. she had another fit, which lasted about two minutes. As the os was now sufficiently dilated, I endeavoured to produce uterine contraction by exciting the os, and grasping the uterus over the abdomen; in this $\mathbf{I}$ succeeded, but as it contracted only when so excited, I imitated the natural process by intermissions, the head hardly seeming to advance, and being still at the brim, I applied the long forceps and extracted the child, dead, at half-past twelve; the placenta followed in about ten minutes, and the uterus was fully contracted. During the whole of this process there was no recurrence of the convulsions, and the patient remained in a state of quiescence, apparently asleep, breathing freely without stertor, until half-past two A. M., when she had another attack. I now removed the hair and applied cold to the head, threw up an enema of infusion of senna, and, the feet being warm, applied nustard cataplasms to the calves of the legs; pupils immovably contracted; pulse small, but not hard. The convulsions still continued to recur at intervals of about three-quarters of an hour, and I began to despair for the life of my patient, when it occurred to ine that this was a case which warranted the use of opium, with a view to allay the morbid sensibility of the nerrous system, upon which I considered the attacks now depended. I therefore administered thirty drops of the tincture, when she almost immediately fell into a protound coma, and I left her at six in the moraing.

Jan. 1.-Nine A. M. : A very slight convulsion about an hour and a half previous to my visit; pulse eighty, soft; coun- tenance placid; extremities warm; pupils not sensible to the stimulus of light, but contracting and dilating irregularly; breathing free. As there had been no action of the bowels, $\mathbf{I}$ put a drop of croton oil and ten grains of calomel mixed with a little honey upon the tongue. Six P.M.: Still comatose; pupils slightly sensitive; purgative dose has acted freely; bladder empty.

Jan. 2.-Consciousness gradually returning; reaction commenced; face flushed; pulse full, but soft; bowels still acting freely; lochia rather scanty; cloths wrung out of hot water to be applied to the pubic region; continue cold to the head; to take a saline draught of citrate of potass and antimonial wine every three hours.

Jan. 3.-Consciousness rapidly returning; inquires as to her state; lochial discharge sufficient; tongue clean; pulse natural has taken plentifully of gruel; the saline has acted freely on the bowels and kidneys.

Jan. 8.- Progressing very satisfactorily; no head-ach; all the secretions natural; the breasts, which began to enlarge on the fourth day, are now soft and flaccid; consciousness perfect; memory unimpaired.

Feb. 1.-The convalescence has been gradual and regular, and the patient has resumed her accustomed avocations in her usual good health.

The above case demonstrates the good effects derived from rather extensive bloodletting, without subjecting the patient to the excessive debility and distressing headach which universally follows the abstraction of the enormous quantity of blood recommended and practised by some of our best authorities, and also the immediate relief which followed the taking of opium after the bleeding had relieyed the cerebral congestion, which was the cause of the convulsions in the earlier period of the attack. My only regret is, that I did not administer the opium sooner after delivery. Had such been the case, I am persuaded that the number of fits would have been materially lessened, if they had not been altogether cluecked.

Copford, Essex, Feb. 1846.

\section{CASE OF OVARIAN DROPSY, FOLLOWED BY} RECOVERY.

By Rrchard Eager, Esq., Surgeon, Guilldford.

Tre termination of a case of ovarian dropsy which lately occurred under my personal observation, is so rare, that I am induced to forward the details of it for publication in THE LANCET.

Mrs. - - aged twenty-eight years, after the birth of her first and only child, now three years old, suffered from attacks of inflammation of the left ovar'y and phlegmasia dolens in the left leg and thigh, the effects of which left her in an enfeebled state of health for several months.

On the 22nd July, 1845 , I was consulted by her in reference to a tumour, abont the size of a fully develoned fotal head, occupying the left iliac region, easily defined to be circumscribed, moveable, and extending toward the right side, somewhat beyond the median line of the abdomen, having a smooth and even surface, and giving an obscure sense of fluctuation on percussion; an examination per vaginam manifested a healthy condition of the uterus, although it was somewhat altered in its position, the fundus being thrown forward, whilst its cervix rested on the recto-vaginal septum :- from these symptoms $I$ diagnosed the disease to be encysted dropsy of the left ovarium; and in this conclusion I was fortified by the opinion of Dr. Lever, who had seen the patient under her former illness, and who was also consulted on the present occasion.

The patient, in the history she gave of her ailment, traced the commencement of it to her recovery from her former illness; and, as it had made no advance in size, during a period exceeding two years, it was hoped it might continue in a quiescent state. Our attentions were therefore directed to the maintenance of the general health, and the promotion of the healthy functions of the system, by regulated exercise, diet, \&c. \&c. The compound iodine ointment was used freely over the site of the enlargement, and the hydriodate of potash with a bitter given three times a day.

From this time, however, the disease assumed a more active character, and advanced with such rapidity, that, by the beginning of November, the patient had attained the size of a woman at the full period of restaticn, the ovarian tumour occupying the abdominal cavity from the pubes to the ensiform cartilage, producing great inconvenience and distress by its pressure on the diaphragm and surrownding viscera, and tap- 